\title{
Modelling Evacuation using Escalators: a London Underground Dataset
}

\author{
Michael J. Kinsey, Edwin R. Galea and Peter J. Lawrence \\ Fire Safety Engineering Group, \\ University of Greenwich, UK \\ $\{$ m.j.kinsey, e.r.galea. p.j.lawrence\}@gre.ac.uk
}

\begin{abstract}
This paper presents a brief analysis of an escalator human factors dataset collected in a London Underground (subway) station in England. The data analysis highlights and quantifies a variety of escalator human factors. Using the buildingEXODUS evacuation software, a series of evacuation scenarios of a hypothetical underground station are then presented. The simulation results demonstrate that escalator strategies and associated human factors can have a considerably influence upon an evacuation compared to using stairs alone.
\end{abstract}

Keywords: escalator, evacuation, modeling, pedestrian, human factors, underground, subway, transit station

\section{$1 \quad$ Introduction}

The development and expansion of underground (subway) stations, often located deep underground, has been possible with the introduction of escalators capable of efficiently transporting large volumes of people [1]. As a result, underground stations are reliant upon escalators for circulation and in many cases emergency evacuation. Despite this, few studies have attempted to quantify human factors associated with escalator usage (microscopic analysis), the majority of past studies focusing on establishing capacity (macroscopic analysis) rather than usage behaviours [2-4].

As such, it is uncertain how human factors associated with escalator usage impact escalator performance in both circulation and evacuation situations. It is also uncertain whether human factors associated with escalator usage has a cultural component. To address these issues, escalator human factors data within three underground station environments in Spain (Barcelona) [5], China (Shanghai) [6] and England (London) have been collected. In each location the same methodology for data collection and analysis was used. This paper presents an overview of the analysis for the London dataset. This data has been implemented within the buildingEXODUS escalator model [7]. In addition, a series of evacuation scenarios has then been simulated using the buildingEXODUS evacuation software [7]. These explore the influence of the escalator human factors and operational strategies upon an evacuation.

adfa, p. 1, 2011.

(C) Springer-Verlag Berlin Heidelberg 2011 


\section{Data Collection}

The data was collected in the Paddington Underground station in London, England. The station links the underground rail network to the mainline national rail services and also forms part of the Heathrow airport express/connect coach service. In addition, it links four underground tube lines (Bakerloo, Circle, District, and Hammersmith \& City). As such many commuters and international travellers pass through the station every day. The footage of two adjacent escalators and an adjacent stair was collected over a period of two days. The escalators were moving in opposite directions. Each escalator had a vertical drop of $3.65 \mathrm{~m}$ with a horizontal length of $8.78 \mathrm{~m}$ and horizontal speed of $0.5 \mathrm{~m} / \mathrm{s}$. The adjacent three lane stair (separated by two hand rails) comprised of two flights connected via a single landing (see Fig. 1). The escalators/stair linked the ticket hall level of the underground station to the adjoining mainline railway station platform level.

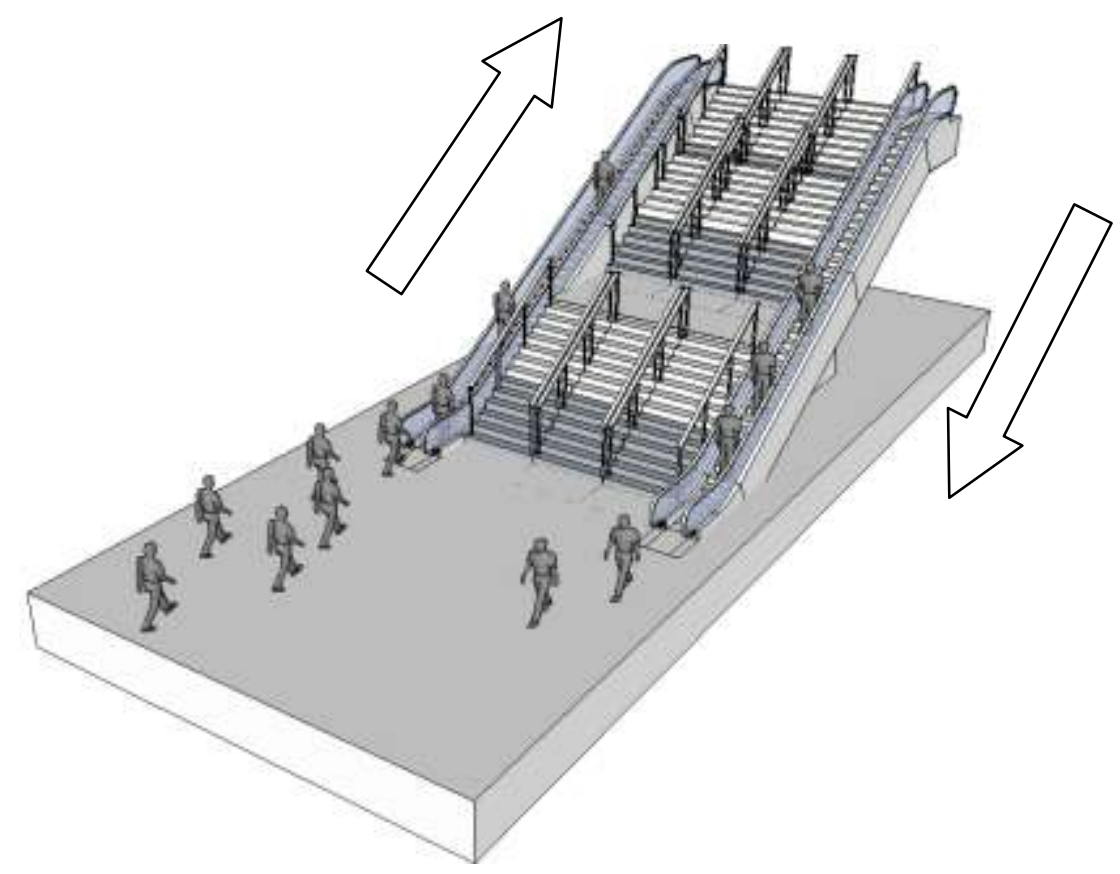

Fig. 1. Escalator/stair configuration (not to scale)

Data was collected via video footage in approximate 20 minute segments during the morning rush-hour, afternoon non-rush hour and evening rush-hour for two days $(2 \mathrm{x}$ $3 \times 20=120 \mathrm{~min}$ of footage). 


\section{Data Analysis}

The following section presents a brief overview of the data analysis. In total, 11,019 pedestrians were recorded: 6,123 on the escalators and 4,896 on the stair. More males $(59.3 \%(3,629))$ than females $(40.7 \%(2,494))$ were observed using each escalator.

\subsection{Escalator/Stair Usage}

Combining the data from the three measurement periods, the majority of pedestrians travelling in the up direction elected to use the escalator (67.0\%) compared the adjacent stair $(\chi 2=620.0, p<0.05)$. However, in the down direction the majority of pedestrians elected to use the adjacent stair $(55.3 \%)(\chi 2=63.0, p<0.05)$. Considering each period separately, in the morning, the overall trend of the escalator being more preferential in the up direction $(75.3 \%)(\chi 2=539.1, \mathrm{p}<0.05)$ and stair in down direction $(64.0 \%)(\chi 2=63.0, p<0.05)$ was also observed. However, during both the afternoon and evening periods, the escalator was the most preferred device irrespective of direction (afternoon (65.9\%): $\chi 2=105.2, \mathrm{p}<0.05$, evening $(53.7 \%): \chi^{2}=4.6, \mathrm{p}<0.05$ ). Overall, the results highlight that the escalator was the most used device in all time periods for both directions with the exception of the morning down direction.

\subsection{Walker/Rider Usage}

Of the 6,123 escalator users recorded, the majority rode the escalator (74.9\%) with the remaining electing to walk. Significantly more males $(29.2 \%)$ elected to walk compared to females $(19.3 \%)(\chi 2=77.0, \mathrm{p}<0.05)$. There was a significant difference between the number of walker/riders in each period $\left(\chi^{2}=1.8, \mathrm{p}<0.05\right)$. Regardless of direction, in the evening periods there were significantly more walkers $(21.0 \%)$ than in the afternoon periods $(15.6 \%)(\chi 2=16.3, \mathrm{p}<0.05)$. In the morning periods there were significantly more walkers $(33.5 \%)$ than in the afternoon $(\chi 2=147.9, \mathrm{p}<0.05)$ and evening periods $(\chi 2=91.404, \mathrm{p}<0.05)$.

Overall there were approximately the same proportion of walkers for both the up $(25.2 \%)$ and down $(25.1 \%)$ directions $(\chi 2=0.03, \mathrm{p}>0.05)$. Considering time period, this trend continued for the morning periods were a similar proportion of walkers for both the up $(34.5 \%)$ and down escalator $(32 \%)(\chi 2=1.8, p>0.05)$ was observed. Similarly for the afternoon periods there was a comparable proportion of walkers for both the up $(15.3 \%)$ and down escalator $(15.9 \%)(\chi 2=0.09, \mathrm{p}>0.05)$. However, during the evening significantly more walkers were observed on the down escalator $(23.6 \%)$ than on the up escalator $(19.1 \%)(\chi 2=5.8, \mathrm{p}<0.05)$.

The results show that time period influences the proportion of walkers/riders. Pedestrians during the rush-hour periods appear more motivated (reflected in the higher proportion of walkers) than during the non-rush hour periods. The combination of time period and direction of travel only appeared to influence the proportion of walk- 
ers/riders in the evening. Here significantly more walkers were recorded in the down direction.

\subsection{Side Usage}

Analysis of the side usage data identified that there was a common side preference for riders to typically use the right side $(88.4 \%)$ and walkers to use the left side $(78.2 \%)$ of each escalator $(\chi 2=5,853.6, p<0.05)$. This trend was more strong for the up direction $(\chi 2=4284.5, p<0.05)(91.6 \%$ riders right $/ 82.9 \%$ walkers left $)$ than in the down direction $(\chi 2=1699.9, p<0.05)(83.7 \%$ riders, right $/ 71.4 \%$ walkers left $)$. This suggests that those on the up escalator conformed more to the common side preference behaviour than those on the down escalator. This may be due to more pedestrians typically simultaneously using the escalator in the up direction. In turn this may have prompted more pedestrians to conform to either riding on the right side or walking on the left side through not wanting to inconvenience other escalator users.

\subsection{Walker Speeds}

In total 810 escalator walker speeds were recorded. The walker speeds were calculated using the horizontal distance travelled and represent the relative speed that pedestrians walked in relation to the escalator (i.e. do not include the escalator speed). A large majority of walkers were male $(70.7 \%(572))$. More walkers were observed in the morning $(54.3 \%$ (441)) and evening $(32.2 \%(261))$ than in the afternoon $(13.4 \%$ $(108)$ ). Overall average walker speeds were faster in the down direction $(0.82 \mathrm{~m} / \mathrm{s})$ than in the up direction $(0.70 \mathrm{~m} / \mathrm{s})(\mathrm{p}<0.05)$. On average males walked $13.33 \%(0.1$ $\mathrm{m} / \mathrm{s})$ faster than females $(\mathrm{p}<0.05)$. There was no significant difference between walker speeds between each period $(p>0.05)$. The results suggest that gender and direction of travel influence escalator walker speeds; however, time period does not.

\subsection{Flow-rates}

The maximum escalator flow-rate was $75 \mathrm{ped} / \mathrm{min}$ in the up direction during the morning rush-hour period. During this period pedestrians moving in the up direction were funnelled into using the escalator due to the adjacent stairs being crowded with pedestrians moving down in the opposite direction. As such, pedestrians moving in the up direction had little choice to use the adjacent stair. During this peak-flow rate period there were a high proportion of riders $(68 \%)$ with approximate even usage of both the left and right side of the escalator: each side was fully utilised. A slightly higher proportion of males $(62.8 \%)$ were also recorded during this period. The majority of pedestrians $(60.7 \%)$ carried items of luggage during this period. However, most were small items (i.e. only a rucksack $(26.0 \%)$ or only a handbag $(20.8 \%)$ ). As such it is expected that this did not contribute to decreasing the flow-rate. 


\section{Evacuation Simulations}

A series of evacuation scenarios have been performed using the buildingEXODUS evacuation software [7]. This software includes an escalator and associated agent model which have been described in other publications [6-8]. A description of the geometry, escalator attributes, population and scenarios are presented followed by the simulation results.

\subsection{Geometry}

The building used for the simulations was a hypothetical underground station (see Fig. 2).

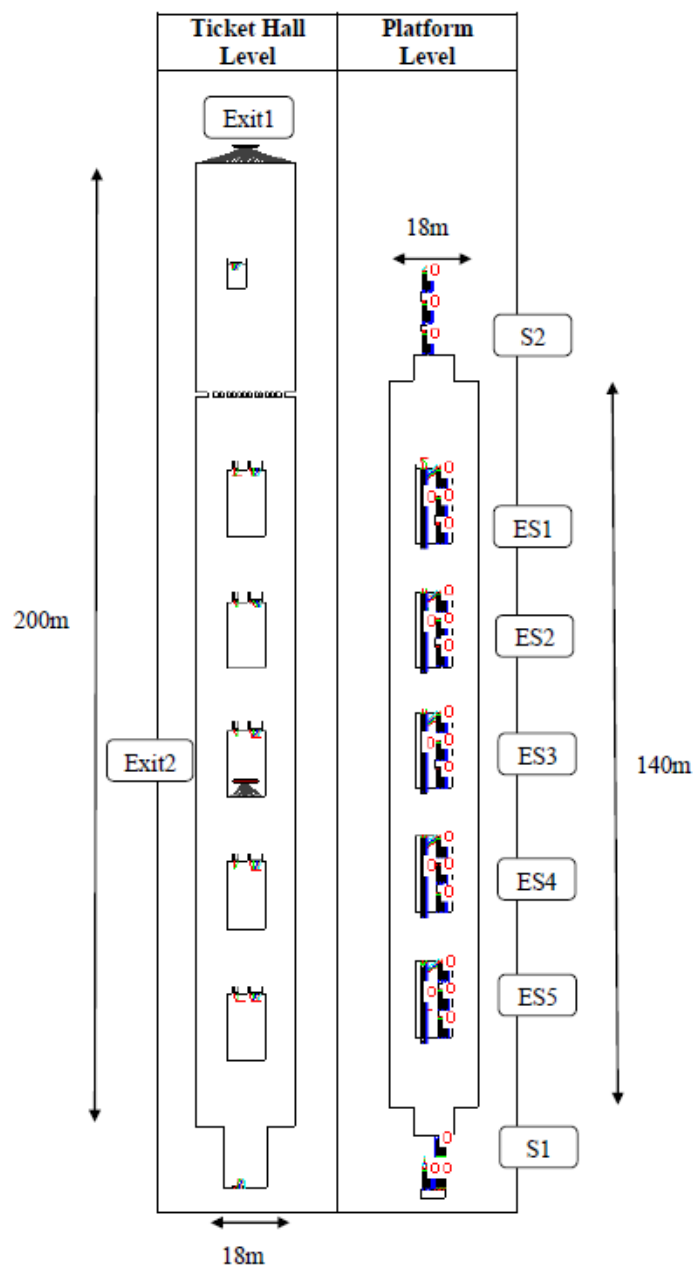

Fig. 2. Hypothetical underground station geometry $(\mathrm{ES}=$ Escalator/Stair, $\mathrm{S}=\mathrm{Stair})$ 
The geometry consisted of 2 levels. The lower level contained a double-sided platform below ground connected via 5 escalators, each with adjacent stairs, to a ticket hall level above. The ticket hall level is where the exits of the station are located. In addition, an emergency stair was positioned at either end of the platform. The platform was $18 \mathrm{~m}$ wide and approximately $140 \mathrm{~m}$ long. Each escalator/stair enclosure linking the platform to the ticket level was approximately $7.5 \mathrm{~m}$ in width and $15 \mathrm{~m}$ in length. The total area of the platform was $2,407.5 \mathrm{~m}^{2}$. Each escalator had a width of $1.0 \mathrm{~m}$, height of $6.29 \mathrm{~m}$ and horizontal length of $15.5 \mathrm{~m}$ with a horizontal speed of $0.5 \mathrm{~m} / \mathrm{s}$. Each stair had a width of $2.3 \mathrm{~m}$, height of $6.29 \mathrm{~m}$ and horizontal length of $13.62 \mathrm{~m}$; consisting of 3 flights of stairs connected via two landings.

The geometry had two exits (Exit 1 and Exit 2) both located on the ticket hall level (see Fig. 2). Exit 1 was $18 \mathrm{~m}$ in width and Exit 2 was $7 \mathrm{~m}$ in width, both representing an open plan exit without doors. The maximum travel distance to Exit 1 and 2 was $67.3 \mathrm{~m}$ and $68.3 \mathrm{~m}$ respectively from the platform level.

\subsection{Population}

Within each scenario agents were modelled as non-connected individuals and were not constrained by groups. The demographics of the agent were assigned according to the default population within buildingEXODUS, representing a broad cross-section of attributes and capabilities [7]. The default stair walker speeds used in buildingEXODUS [7] were derived from those collected by Fruin [9]. The escalator walker speeds used in the scenarios were derived from the London Underground dataset (see above).

The NFPA 130 Standard for Fixed Guideway Transit and Passenger Rail Systems 2010 [10] includes recommendations for maximum occupancy levels within train stations. It states that the maximum agent load for a train station shall be based on trains simultaneously arriving at each platform within a station plus the simultaneous arrival of individuals entering the station for each train during peak times. The 1996 Rolling Stock 7 car design (currently used on the Jubilee line in the London Underground) spans a length of approximately 124 metres which is similar to the platform length in the hypothetical geometry. Such trains allow a maximum train capacity of 964 passengers (234 sitting, 730 standing) [11].

In addition to representing occupants simultaneously arriving on trains at each platform, those occupants that would already be waiting on each platform was also represented. The platform waiting occupancy has been proposed to be $50 \%$ of the maximum train capacity. In the given geometry this equates to $2 \times 482=964$ agents (for two trains on either side of the platform). This waiting occupancy frequency is considered to be the upper limit of the maximum platform occupancy. All occupants initially on the platform level were assumed to be located on the platform itself and no representation of occupants disembarking trains is represented. Combined with the 
maximum capacity for a train on each platform gives a total platform level occupancy of 2,892 agents. The total occupancy on the platform is considered maximal and meant that on average the platform effectively had approximately $1.2 \mathrm{ped} / \mathrm{m}^{2}$ which corresponds to Fruin's level of service E described as "Standing in physical contact with others is unavoidable" [9].

Within all scenarios, approximately an even number of agents initially on the platform level elect to use each of the five escalators/stairs to traverse to the ticket hall above as part of their egress. The initial agent starting locations on the platform were specified such that these frequencies for device usage were achieved with agents using their nearest escalator/stair. This was to ensure that any single escalator/stair was not disproportionally oversubscribed (so extending the evacuation). Though uneven escalator/stair loading would decrease the efficiency of an evacuation, the focus of this investigation is how escalator strategies and human factors influence an evacuation. Approximately $10 \%$ (388) of all platform agents were assumed to use the emergency stairs at either end of the platform. This represents the decreased usage (compared to the main escalators/stairs) due to the expected lack of familiarity with stairs due to not being used during normal circulation situations.

The ticket hall level above was assumed to be initially occupied by the same number of waiting agents on a single platform (964). This was intended to represent both entering and exiting agents to the station. The frequency of agents initially on the ticket level were assigned to use each exit according to the proportion of the aggregated width each exit provided; with $28.0 \%$ (270) assigned to Exit 1 and $72.0 \%$ (694) assigned to Exit 2. As with the escalator/stair assignment on the platform level, this was to minimise the influence of uneven usage of exits and the potential decrease in evacuation efficiency caused. Combining the total platform and ticket level occupancy, the entire occupancy of the station was 3,856 agents.

Passenger response times for underground station environments are not well documented and so response times were specified using the Chinese Design Code for Subway stations [12]. This specifies an average evacuation response time of 60 seconds for people in a transit station. Such specifications have been typically used to assess upper limit design requirements. With this in mind, agents within the modelled scenarios were randomly uniformly assigned a response time range between 0-120 seconds (0-2 minutes) with an average of 60 seconds.

\subsection{Scenarios}

A series of 12 evacuation scenarios were performed exploring the influence of different escalator strategies and escalator human factors upon the evacuation (see Table 1). The scenarios investigated are:

- Scenario 1: Only the stairs were used with the escalators not being used.

- Scenario 2: The stairs and escalators could be used however, the escalators were static: agents could walk up the escalators if they chose to. No data was 
collected with regards to static escalator walker speeds in each of the studies. As such agents assessed whether to use a static escalator based on their stair walker speed. If agents elected to use the static escalator they would use their stair walker speed to traverse the escalator.

- Scenarios 3-8: Explored the impact of different human factors upon an evacuation. This included analysing the influence of the number of escalator/stair users, number of walkers/riders, ride side usage, and different congestion threshold values [7].

- Scenarios 9-11: Focused on the influence of escalators/stairs being unavailable.

- Scenario 12: Employed the escalator human factors data collected from the London Underground presented in Section 3. The proportion of escalator/stair users, walkers/riders and side usage values were derived from the up morning rush-hour data [8]. This was considered appropriate considering potential increased levels of motivation during such periods.

Each scenario was run a total of five times and the average results are presented in Table 2.

Table 1. Evacuation sceanrios with attribute values for the escalator model

\begin{tabular}{|c|c|c|c|c|c|c|c|c|}
\hline \multirow[t]{2}{*}{ Scenario } & \multirow{2}{*}{$\begin{array}{c}\text { Escalator } \\
\text { Motion } \\
\text { (Moving/ } \\
\text { Static) }\end{array}$} & \multicolumn{2}{|c|}{$\begin{array}{l}\text { Escalator/Stair } \\
\text { (\% of agents) }\end{array}$} & \multicolumn{2}{|c|}{$\begin{array}{l}\text { Walker/Rider } \\
\text { (\% of agents) }\end{array}$} & \multicolumn{2}{|c|}{$\begin{array}{c}\text { Rider Side } \\
\text { Usage } \\
\text { (\% of agents) }\end{array}$} & \multirow{2}{*}{$\begin{array}{c}\text { Congestion } \\
\text { Threshold } \\
\text { (CT) } \\
\left(\text { ped } / \mathbf{m}^{2}\right)\end{array}$} \\
\hline & & Escalator & Stair & Walker & Rider & Left & Right & \\
\hline 1 & - & 0 & 100 & - & - & - & - & - \\
\hline 2 & Static & - & - & - & - & - & - & 0 \\
\hline 3 & Moving & 50 & 50 & 0 & 100 & - & 100 & - \\
\hline 4 & Moving & - & - & 100 & 0 & - & - & 0 \\
\hline 5 & Moving & - & - & 0 & 100 & 50 & 50 & 0 \\
\hline 6 & Moving & - & - & 0 & 100 & 0 & 100 & 0 \\
\hline 7 & Moving & 50 & 50 & 100 & 0 & 0 & 0 & 1 \\
\hline 8 & Moving & 50 & 50 & 100 & 0 & 0 & 0 & 2 \\
\hline 9 & Moving & - & - & 100 & 0 & - & - & 0 \\
\hline 10 & Moving & - & - & 100 & 0 & - & - & 0 \\
\hline 11 & Moving & - & - & 100 & 0 & - & - & 0 \\
\hline 12 & Moving & 75.3 & 24.7 & 34.5 & 65.5 & 5.4 & 94.6 & 1 \\
\hline
\end{tabular}

\subsection{Results}

A summary of results for each scenario is presented in Table 2 with evacuation curves shown in Fig. 3. Scenario 1 represents a situation akin to potential practice in an actual evacuation whereby the escalators are not used and people are required to use only the stairs. This scenario produced the second longest Total Evacuation Time (TET) of 429 s with the platform taking $337 \mathrm{~s}$ to clear. On average agents spent just over one minute waiting in congestion with the average Cumulative Wait Time (CWT) being 67.6s. Another common practice during an evacuation is to turn the 
escalators off, but allow agents to walk on the devices. If it is assumed that agents elect to use a device based on the shortest time system (Scenario 2), the TET reduces to $353 \mathrm{~s}$, a decrease of $17.8 \%$ (76s). In addition, the platform clearance time also reduced to $273 \mathrm{~s}$, a decrease of $19.0 \%(64 \mathrm{~s})$. On average approximately a quarter of agents $(26.1 \%)$ who made an escalator/stair choice, used an escalator. This reflects the influence of the increased width of the stairs compared to the static escalator.

Table 2. Average TET, PET, CWT, Platform Clearance Time, Door 1 and 2 Exit times for each scenario (average of 5 simulations)

\begin{tabular}{|c|c|c|c|c|c|c|c|c|}
\hline Scenario & $\begin{array}{c}\text { Avg } \\
\text { TET } \\
(\mathbf{s e c})\end{array}$ & $\begin{array}{c}\text { Avg } \\
\text { PET } \\
(\mathbf{s e c})\end{array}$ & $\begin{array}{c}\text { Avg } \\
\text { CWT } \\
\text { (sec) }\end{array}$ & $\begin{array}{c}\text { Platform } \\
\text { Clearance } \\
\text { Time } \\
(\mathbf{s e c})\end{array}$ & $\begin{array}{c}\text { Overall: } \\
\text { \% Time } \\
\text { Saved } \\
\text { Compared } \\
\text { to Stairs } \\
\text { Only }\end{array}$ & $\begin{array}{c}\text { Overall: } \\
\text { \% Time } \\
\text { Saved } \\
\text { Compared } \\
\text { to } \\
\text { Stair+Static } \\
\text { Escalator }\end{array}$ & $\begin{array}{c}\text { Platform: } \\
\text { \% Time } \\
\text { Saved } \\
\text { Compared } \\
\text { to Stairs } \\
\text { Only }\end{array}$ & $\begin{array}{c}\text { Platform: } \\
\text { \% Time } \\
\text { Saved } \\
\text { Compared } \\
\text { to } \\
\text { Stair+Static } \\
\text { Escalator }\end{array}$ \\
\hline $\mathbf{1}$ & 429 & 199 & 67.6 & 337 & - & -21.6 & - & -23.4 \\
\hline $\mathbf{2}$ & 353 & 170 & 40.5 & 273 & 17.8 & - & 19.0 & - \\
\hline $\mathbf{3}$ & 380 & 174 & 42.7 & 307 & 11.5 & -7.7 & 8.8 & -12.6 \\
\hline $\mathbf{4}$ & 325 & 163 & 36.3 & 246 & 24.3 & 8.0 & 27.0 & 10.0 \\
\hline $\mathbf{5}$ & 339 & 170 & 36.6 & 268 & 21.1 & 4.0 & 20.4 & 1.7 \\
\hline $\mathbf{6}$ & 361 & 175 & 40.9 & 291 & 15.8 & -2.4 & 13.5 & -6.8 \\
\hline $\mathbf{7}$ & 321 & 160 & 32.6 & 247 & 25.1 & 9.0 & 26.7 & 9.6 \\
\hline $\mathbf{8}$ & 315 & 159 & 31.5 & 229 & 26.7 & 10.8 & 31.9 & 15.9 \\
\hline $\mathbf{9}$ & 367 & 173 & 46.2 & 270 & 14.4 & -4.1 & 19.9 & 1.1 \\
\hline $\mathbf{1 0}$ & 421 & 183 & 56.9 & 327 & 1.9 & -19.3 & 2.9 & -19.9 \\
\hline $\mathbf{1 1}$ & 564 & 230 & 95.7 & 468 & -31.4 & -59.8 & -39.0 & -71.6 \\
\hline $\mathbf{1 2}$ & 336 & 167 & 35.1 & 254 & 21.6 & 4.7 & 24.5 & 6.9 \\
\hline
\end{tabular}

In Scenario 3 the escalators were active, agents were evenly assigned to use both the escalators/stairs and all escalator users rode on the right side. During this scenario a small increase (7.7\% (27s)) in TET to 380s was observed compared to the static escalator case (Scenario 2). If it is now assumed that agents elect to use a device based on the shortest time system with all escalator users walking (Scenario 4), the TET reduces even further to $325 \mathrm{~s}$. This represents a decrease of $24.3 \%$ (104s) compared to the stair only scenario and was one of the fastest scenarios. Similarly the platform clearance time also decreased by $27.0 \%$ (91s) to $246 \mathrm{~s}$ compared to the stair only scenario. A reduction in average CWT by almost a half $(46.3 \%$ (31.3s)) to $36.3 \mathrm{~s}$ was also recorded compared to the stair only scenario. On average a higher proportion of agents elected to use the escalator $(59.5 \%)$ compared to the stairs $(40.5 \%)$. An increased overall average flow-rate of agents onto the escalators $(87.7 \mathrm{ped} / \mathrm{min})$ was observed compared to Scenario $3(68.3 \mathrm{ped} / \mathrm{min})$ where agents were only allowed to board the right side and ride the escalator.

In Scenario 5 all escalator users were assumed to ride with an even number adopting each side. In this scenario an average decrease in TET of $10.8 \%(41 \mathrm{~s})$ and $12.7 \%$ 
(39s) in platform clearance time can be seen compared to when escalator users all rode on the right side (Scenario 3). Compared to when all escalator users walked (Scenario 4$)$, only a slight increase in TET $(5.2 \%(17 \mathrm{~s}))$ and platform clearance time $(9.2 \%(23 \mathrm{~s}))$ was recorded.

Scenario 6 is identical to Scenario 3 where all escalator users rode on the right side, except that agents selected to use a device according to which one they expect they could traverse in the shortest time (i.e. the shortest time system [7]) instead of evenly being assigned. A slight decrease in TET by $4.7 \%$ (18s) was observed compared to Scenario 3 with a similar reduction $(5.1 \%(16 \mathrm{~s}))$ in platform clearance times. Approximately an even number of agents used each escalator/stair with the average PET/CWT being similar in both scenarios.

Scenario 7 extended Scenario 4 by using the hybrid device selection system [7]. In this scenario a Congestion Threshold (CT) value of $1 \mathrm{ped} / \mathrm{m}^{2}$ was set with even usage of each escalator/stair imposed before the CT was reached. The scenario produced one of the shortest TETs (321s) and platform clearance times (247s). It was comparable to Scenario 4 where all agents used the shortest time system when choosing to use an escalator/stair. In Scenario 4 approximately an even number of agents used each escalator/stair. As such assigning an even proportion of agents to use each device before a given level of congestion was reached in Scenario 7 had little effect. A similar phenomenon occurred in Scenario 8 where the altered CT of $2 \mathrm{ped} / \mathrm{m}^{2}$ had little influence upon the overall evacuation compared to Scenario 4.

The concept of reducing escalator/stair availability is introduced in Scenario 9. In this scenario ES1 was unavailable with agents who would have used ES1 evenly using the remaining escalators/stairs. In addition, the shortest time system was used with all escalator users walking. Both the TET and platform clearance times were marginally longer by $12.9 \%(42 \mathrm{~s})$ and $9.8 \%$ (24s) respectively compared to when all escalators/stairs were available (Scenario 4). Scenario 10 extends the escalator/stair unavailability concept to two escalator/stairs (ES1 and ES5) being unavailable at either end of the platform. Here an average TET of 421s and platform clearance time of $327 \mathrm{~s}$ was recorded which is similar to the time taken to evacuate the station in the stair only scenario (Scenario 1). Despite this, the evacuation rate was notably higher than the stair only case for a large proportion of the TET: between approximately $42.8 \%$ (180s) $-87.9 \%$ (370s) of the TET (see Table 2). This was due to the added vertical throughput afforded by the available escalators and escalator users all walking. The TET from Scenario 10 increased by $29.6 \%$ (96s) compared to Scenario 4 where all escalators/stairs were available. The final scenario involving escalator/stair unavailability was Scenario 11 where 3 escalators/stairs were unavailable. This scenario produced the longest TET of all scenarios at 564s, representing a 73.6\% (239s) increase compared to Scenario 4 where all escalator/stairs were available. In all scenarios involving escalators/stairs being unavailable approximately an even number of agents used each device. The escalator/stair availability results suggest that there may not be a linear increase in time with linear decrease of escalators/stairs availability. This 
demonstrates that escalator human factors impact the extent to which platform clearance times are increased when escalators/stairs are unavailable.

The final scenario incorporated the data presented in Section 3 into the escalator model in buildingEXODUS [7]. Overall average results (see Table 2) and evacuation curves (see Fig. 3) were similar to that of Scenario 5 where all agents rode on both sides of the escalators. This reflects the similar influence of having separate walker/rider lanes compared to all agents riding using both sides. Since only $5.4 \%$ of riders in the data were observed to use the walker lane, in the model this meant that few agents that were riders would have blocked walkers from walking up the walker lane (i.e. this further contributed to the similarities with Scenario 5). In addition, since the levels of congestion increased quickly at the base of each escalator/stair, the influence of the CT being set to $1 \mathrm{ped} / \mathrm{m}^{2}$ was reduced. Thus, most agents selected a device using the shortest time system in both Scenario 5 and Scenario 11.

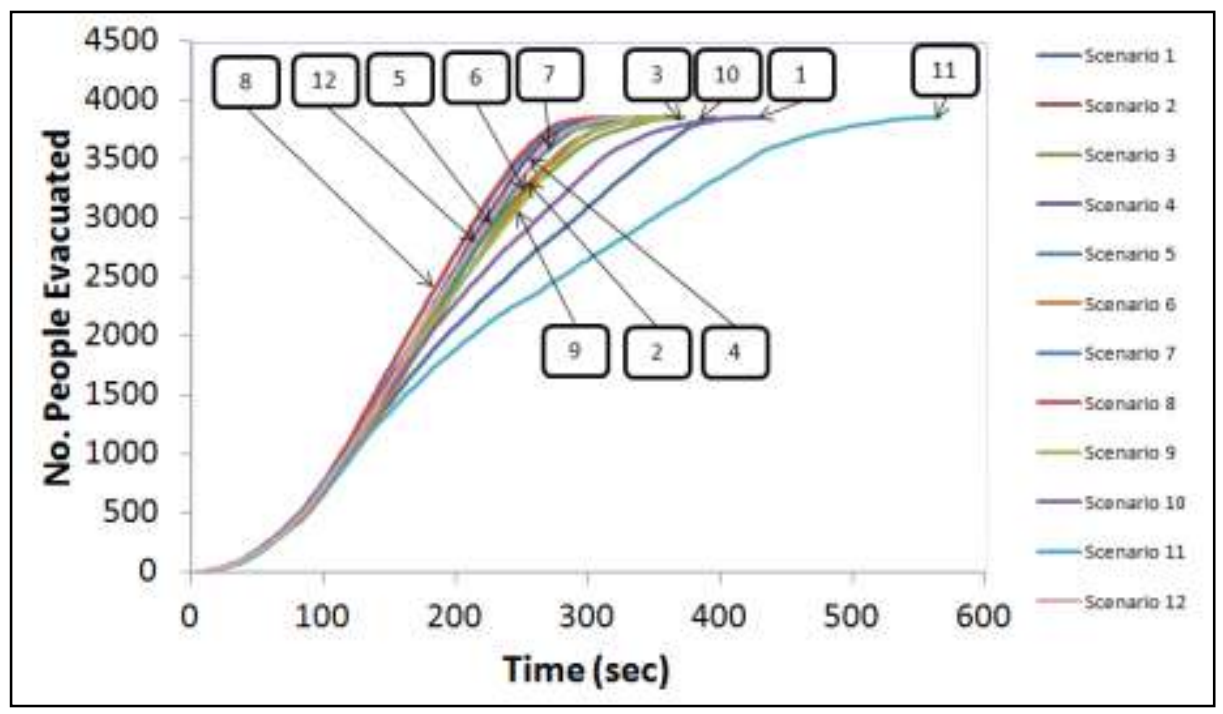

Fig. 3. Evacuation curves for each scenario

In all scenarios agents initially on the ticket hall level were among the first to evacuate the station so varying escalator strategies or associated human factors had little influence on those agents. Consequently the evacuation curves for all scenarios (see Fig. 3) are similar for the first 964 agents in each scenario (i.e. the total ticket hall population). The remaining agents evacuated from the platform level below so were influenced by the different escalator strategies and escalator agent behaviour. As such the evacuation curves begin to differ after approximately the ticket hall agents evacuated. 


\section{Conclusion}

This paper has presented a brief overview of the analysis of an escalator human factors dataset collected in a London Underground station. The analysis showed the escalators to be the most used devices compared to the adjacent stairs with most escalator users electing to ride rather than walk. Escalator users were observed to strongly adopt a common side preference whereby riders used the right side and walkers use the left side. Escalator users typically walked faster in the down direction and males walked faster than females. When peak flow-rates were observed, approximately an even number of escalator users occupied both the right and left sides with a higher proportion of walkers typically carrying small items e.g. handbags, rucksacks etc. Some human factors were shown to be influenced by direction of travel and time period.

Results from a series of evacuation simulation scenarios were presented, based on the buildingEXODUS escalator model which explored the influence of escalator strategies and human factors upon evacuation efficiency. The evacuation analysis demonstrated that even the provision of static escalators can have a considerable influence upon an evacuation compared to using stairs alone. Furthermore, the provision of a moving escalator has been shown to decrease overall evacuation times by up to approximately $25 \%$ compared to using stairs alone and around $10 \%$ compared to using static escalators. Results have shown that little decrease in TET was observed when all escalator users walked compared to if they all rode. This is an important observation and suggests that there is little added benefit if the population walk up the moving escalator - as this reduces tread utilisation. Thus, urging escalator users to ride on both sides of an escalator, rather than walking up the moving escalator, has the advantage of reducing the likelihood of users tripping on the escalator without significantly increasing the TET.

Scenarios where escalators/stairs were rendered unavailable had a considerable impact upon the evacuation, as expected. In those scenarios, increases in TET of up to $60 \%$ and platform clearance times of up to $72 \%$ compared to stairs alone were recorded. Such findings highlight the severity caused by the unavailability of escalators/stairs (e.g. due to fire/smoke, code stipulations, etc), and the need to consider additional provision of vertical egress capacity.

Further investigation is required to assess the extent to which the results are generally applicable. In addition, the human factors escalator data collected from Shanghai, Barcelona and London is being examined to estimate the possible impact of culture on human behaviour associated with the use of escalators. 


\section{Acknowledgements}

Michael Kinsey gratefully acknowledges the support of the Fire Safety Engineering Group of the University of Greenwich and the Engineering and Physical Science Research Council (EPSRC) for providing him with a bursary under their PhD bursary scheme. The authors gratefully acknowledge the support of Kingfell, London Underground Limited and British National Rail in providing access to the facilities for the collection of the escalator data.

\section{$7 \quad$ References}

1. Strakosch, G., Caporale, R.S.: The Vertical Transportation Handbook, The Third Edition, John Wiley \& Sons Inc (2010)

2. Al-Sharif, L.: Escalator Handling Capacity: Standards Versus Practice, Elevator World (1996)

3. Cheung, C., Lam, W.: Pedestrian Route Choices Between Escalator and Stairway in MTR Stations, Journal of Transportation Engineering, Vol. 124, No. 3, pp227-285 (1998)

4. Davis, P., Dutta, G.: Estimation of Capacity of Escalators in London Underground, No 2002-11-01, IIMA Working Papers from Indian Institute of Management Ahmedabad, Research and Publication Department (2002)

5. Kinsey, M.J, Galea, E.R, Lawrence, P.J, Blackshields, D., Hulse, L., Day, R. and Sharp, G.: Modelling Pedestrian Escalator Behaviour, Pedestrian and Evacuation Dynamics (PED) Conference, pp689-695 (2008)

6. Kinsey, M.J, Galea, E.R, Lawrence, P.J.: Extended Model of Pedestrian Escalator Behaviour Based on Data Collected within a Chinese Underground Station, Proceedings of the Human Behaviour in Fire Conference, pp173-182 (2009)

7. Galea, E.R., Lawrence, P.J., Gwynne, S., Filippidis, L., Blackshields, D., Cooney, D.: BuildingEXODUS V5.0 User Guide and Technical Manual, Fire Safety Engineering Group, University of Greenwich (2011)

8. Kinsey, M.J.: Vertical Transport Evacuation Modelling', PhD Thesis, University of Greenwich (2011)

9. Fruin, J.J.: Pedestrian Planning and Design, Metropolitan Association of Urban Designers and Environmental Planners (1971)

10. NFPA - National Fire Protection Association: NFPA 130: Standard for Fixed Guideway Transit and Passenger Rail Systems, Technical Report (2010)

11. Transport for London (TFL): '1996 Rolling Stock', http://www.tfl.gov.uk/corporate/modesoftransport/londonunderground/rollingstock/1630.a spx (2010)

12. Planning Press of China: Code for Design of Subway. GB 50157-2003 (2003) 